\title{
Pirfenidone may revert the epithelial-to-mesenchymal transition in human lung adenocarcinoma
}

\author{
RYOTA KURIMOTO ${ }^{1}$, TAKAHIRO EBATA ${ }^{1}$, SHUNICHIRO IWASAWA ${ }^{1}$, \\ TSUKASA ISHIWATA $^{2}$, YUJI TADA ${ }^{2}$, KOICHIRO TATSUMI $^{2}$ and YUICHI TAKIGUCHI ${ }^{1}$
}

Departments of ${ }^{1}$ Medical Oncology and ${ }^{2}$ Respirology, Graduate School of Medicine, Chiba University, Chiba 260-8670, Japan

Received March 3, 2016; Accepted March 23, 2017

DOI: $10.3892 / 01.2017 .6188$

\begin{abstract}
The epithelial-to-mesenchymal transition (EMT) in cancer is associated with invasion, metastasis and chemoresistance. Recent studies have revealed the increased expression of programmed death-ligand 1 (PD-L1) in cells undergoing EMT. The underlying mechanism of EMT involves transforming growth factor- $\beta$ (TGF- $\beta$ ) and fibroblast growth factor-2 (FGF-2). Pirfenidone and the known EMT-suppressor nintedanib suppress pulmonary fibrosis partially through suppression of TGF- $\beta$. The present study aimed to determine whether pirfenidone has the potential to induce EMT-reversion, using nintedanib as a reference. The human lung adenocarcinoma cell lines A-549, HCC-827, and PC- 9 were treated with TGF- $\beta$ and FGF-2 to induce EMT. The EMT-induced cells were further treated with pirfenidone or nintedanib. Phenotypic alterations associated with EMT were assessed by examining the following: i) The expression levels of E-cadherin, vimentin, fibronectin and slug, using reverse transcription-quantitative polymerase chain reaction (RT-qPCR) and fluorescent immunohistochemistry; ii) cell motility via wound-healing assays; and iii) the expression of PD-L1 using RT-qPCR. The combination of TGF- $\beta$ and FGF-2 successfully induced EMT in all three cell lines, characterized by a significant reduction in E-cadherin expression in the A-549 and HCC-827 cells, increased expression levels of vimentin, fibronectin, slug and PD-L1, and increased cell motility in all three cell lines. Pirfenidone and nintedanib reverted all of these phenotypes, with the exception of unaltered E-cadherin expression in all three cell lines, and inconsistent expression of vimentin in the HCC-827 and PC-9 cells. Thus, pirfenidone and nintedanib have the ability to induce EMT-reversion in human lung adenocarcinoma.
\end{abstract}

Correspondence to: Professor Yuichi Takiguchi, Department of Medical Oncology, Graduate School of Medicine, Chiba University, 1-8-1 Inohana, Chuo-ku, Chiba 260-8670, Japan

E-mail: takiguchi@faculty.chiba-u.jp

Key words: epithelial-to-mesenchymal transition, pirfenidone, nintedanib, programmed death-ligand 1 , lung adenocarcinoma

\section{Introduction}

The epithelial-to-mesenchymal transition (EMT) serves important roles in embryonic development, cancer invasion, metastasis and chemoresistance (1-3). EMT cells demonstrate lower expression levels of epithelial markers, including E-cadherin, and higher expression levels of mesenchymal markers, including vimentin and fibronectin $(1,2)$. These expressional changes occur through the upregulation of transcriptional factors, including the zinc finger proteins, zinc finger E-box binding homeobox (ZEB)1 and 2, the basic helix-loop helix protein Twist, and the Snail family, including Snail and Slug $(1,2)$. Although the underlying mechanisms remain unclear, transforming growth factor- $\beta$ (TGF- $\beta$ ) and fibroblast growth factor-2 (FGF-2) constitute the main EMT-inducing factors in numerous types of cancer $(1,4,5)$. Due to its roles in cancer invasion, metastasis and chemoresistance, the inhibition or reversion of the EMT has been regarded as a promising strategy for treating cancer. Several agents, including a mechanistic target of rapamycin inhibitor (6) and metformin (7), have been reported to suppress EMT in lung cancer. However, effective approaches for inhibiting the EMT have not been established.

Recently, the anti-fibrotic agents pirfenidone and nintedanib have been approved in numerous countries for the treatment of idiopathic pulmonary fibrosis (IPF). Randomized controlled clinical trials have demonstrated that pirfenidone suppresses the deterioration of the percentage forced vital capacity (FVC), with manageable toxicities, in patients with $\operatorname{IPF}(8,9)$. Furthermore, pirfenidone has been revealed to suppress lung fibrosis through the downregulation of TGF- $\beta$, platelet-derived growth factor (PDGF) and collagen synthesis in a hamster model (10-12). In addition, it was shown to suppress liver fibrosis through the downregulation of TGF- $\beta(13,14)$. Nintedanib has been demonstrated to suppress the deterioration of FVC and the incidence of acute exacerbation in patients with IPF $(15,16)$. Additionally, it has been revealed to inhibit fibrosis through the downregulation of extracellular matrix proteins in pulmonary fibroblast cells (17). The expression levels of the receptor tyrosine kinases of PDGF, FGF and vascular endothelial growth factor were observed to be inhibited following treatment with nintedanib (17). Recently, nintedanib was demonstrated to inhibit the early signaling of TGF- $\beta$ by suppressing the phosphorylation of the TGF- $\beta$ type II receptor (18). 
Numerous studies have reported that the relative risk of lung cancer among patients with IPF is 7-14 times higher compared with that in patients without IPF (19-21). Under such circumstances, these agents may soon be widely used for the treatment of patients with lung cancer accompanied by IPF. Thus, elucidating the potential effects of these agents on lung cancer cells is required. Nintedanib, which is assumed to suppress TGF- $\beta$ and FGF, was recently reported to suppress the EMT in ovarian cancer cells in vitro (22). As pirfenidone also has the ability to suppress TGF- $\beta$, it may be useful for suppressing or reverting the EMT. Therefore, the present study aimed to evaluate the effect of pirfenidone on the EMT in human lung cancer and compare its efficacy to the activity of nintedanib.

\section{Materials and methods}

Cells and reagents. The human lung adenocarcinoma cell lines A-549, HCC-827 (American Type Culture Collection, Manassas, VA, USA) and PC-9 (Riken Cell Bank, Tsukuba, Japan) were used throughout the present study. HCC-827 and PC-9 cells have a deletion in exon 19 (del E746-A750) of the epidermal growth factor receptor gene. Cells were cultured as a monolayer in RPMI-1640 medium (Sigma-Aldrich; Merck KGaA, Darmstadt, Germany) supplemented with $10 \%$ fetal bovine serum (FBS), $100 \mathrm{U} / \mathrm{ml}$ penicillin and $100 \mathrm{mg} / \mathrm{ml}$ streptomycin (all Thermo Fisher Scientific, Inc., Waltham, MA, USA) at $37^{\circ} \mathrm{C}$ in a humidified atmosphere containing $5 \% \mathrm{CO}_{2}$. Pirfenidone (Sigma-Aldrich; Merck KGaA) was dissolved in water at a concentration of $1.0 \mathrm{M}$ and stored at $-20^{\circ} \mathrm{C}$. Nintedanib (Selleck Chemicals, Houston, TX, USA) was dissolved in DMSO (Sigma-Aldrich; Merck KGaA) at a concentration of $10 \mathrm{mM}$ and stored at $-20^{\circ} \mathrm{C}$. Prior to use in the experiments, each agent was diluted in RPMI-1640 medium with $10 \% \mathrm{FBS}, 100 \mathrm{U} / \mathrm{ml}$ penicillin and $100 \mathrm{mg} / \mathrm{ml}$ streptomycin. Mouse monoclonal anti-fibronectin antibody (cat. no. F3648) was purchased from Sigma-Aldrich (Merck $\mathrm{KGaA}$ ). The anti-E cadherin antibody was purchased from BD Biosciences (cat. no. 610181; Franklin Lakes, NJ, USA). Anti-mouse IgG Fab2 Alexa Fluor ${ }^{\circledR} 488$ molecular probes (cat. no. 4408S) and anti-rabbit IgG Fab2 Alexa Fluor 555 molecular probes (cat. no. 4413S) were purchased from Cell Signaling Technology, Inc. (Danvers, MA, USA).

In vitro induction and reversion of EMT. EMT was induced by treatment with recombinant human TGF- $\beta$ (PeproTech, Inc., Rock Hill, NJ, USA) and FGF-2 (Cell Signaling Technology, Inc.). Based on preliminary experiments (data not shown), a combination of TGF- $\beta$ (10 ng/ml) and FGF-2 (10 ng/ml) was admixed into the complete medium for induction of EMT following $24 \mathrm{~h}$ of serum starvation. To evaluate the EMT phenotypes, cells harvested at $48 \mathrm{~h}$ after the admixture of the agents were used. Pirfenidone $(0.2$ and $2.0 \mathrm{mM})$ or nintedanib $(0.1$ and $1.0 \mu \mathrm{M})$ was then added to cells in which the EMT had already been induced, with TGF- $\beta /$ FGF- 2 being supplemented continuously. The phenotypic alterations were evaluated after $72 \mathrm{~h}$ of culture with these agents.

Evaluation of cell viability. Cell viability was determined using an MTT assay according to the manufacturer's protocol
(Promega Corp., Madison, WI, USA). Cells were seeded into 96-well culture plates at a density of $1 \times 10^{3}$ cells/well. Cells were allowed to attach for $24 \mathrm{~h}$ prior to drug treatment. Cells were treated with various concentrations of pirfenidone $(0$, $0.02,0.2,2.0$ and $10 \mathrm{mM})$ or nintedanib $(0,0.01,0.1,1.0$ and $10 \mu \mathrm{M}$ ) for $48 \mathrm{~h}$ of culture at a $37^{\circ} \mathrm{C}$. The absorbance at $570 \mathrm{~nm}$ in the resulting solution was measured using the Infinite ${ }^{\circledR} 200$ PRO microplate reader (Tecan Schweiz AG, Seestrasse, Switzerland).

Reverse transcription-quantitative polymerase chain reaction $(R T-q P C R)$. Cells were cultured until $80 \%$ confluence was achieved in 6-well culture plates, the total RNA was extracted using the RNeasy ${ }^{\circledR}$ Mini kit (cat. no. 74104; Qiagen $\mathrm{GmbH}$, Hilden, Germany) and the cDNA was synthesized using the SuperScript ${ }^{\circledR}$ First-Strand Synthesis kit for RT-PCR (cat. no. 11904-018; Thermo Fisher Scientific, Inc.) according to the manufacturer's protocols. The expression levels of various mRNAs were quantified using RT-qPCR with the TaqMan ${ }^{\circledR}$ Gene Expression Assay kit, TaqMan Fast Advanced Master mix (cat. no. 4444557) and StepOnePlus Real-Time PCR system (all Thermo Fisher Scientific, Inc.). A total of $25 \mathrm{ng}$ synthesized cDNA was used for each qPCR reaction. Each sample was measured in triplicate. GAPDH was used for normalization. Relative expression levels were calculated as using the $2^{-\Delta \Delta C q}$ method (23). TaqMan probes for GAPDH, E-cadherin, vimentin, fibronectin, Slug and programmed death-ligand 1 (PD-L1) were purchased from Applied Biosystems (Thermo Fisher Scientific, Inc.; assay identification nos. Hs02758991_g1, Hs01023894_m1, Hs00185584_m1, Hs00365052_m1, Hs00950344_m1 and Hs01125301_m1, respectively). The following thermocycling conditions were maintained: $10 \mathrm{~min}$ at $95^{\circ} \mathrm{C}$, followed by 40 cycles of $15 \mathrm{sec}$ at $95^{\circ} \mathrm{C}$ and $1 \mathrm{~min}$ at $60^{\circ} \mathrm{C}$.

Fluorescent immunohistochemistry. For fluorescent immunohistochemical evaluation, cells were seeded into a 4-well chamber slide (cat. no. 177399; Thermo Fisher Scientific, Inc.) at density of $1 \times 10^{4}$ cells/well and cultured until $80 \%$ confluence was achieved. Cells grown on the chamber slide were fixed with $4 \%$ paraformaldehyde (Sigma-Aldrich; Merck $\mathrm{KGaA}$ ) for $15 \mathrm{~min}$ at room temperature and with acetone (both Sigma-Aldrich; Merck KGaA) for $10 \mathrm{~min}$ at $-20^{\circ} \mathrm{C}$. Non-specific binding was blocked using $1 \%$ bovine serum albumin with $0.2 \%$ Triton X-100 (both Sigma-Aldrich; Merck $\mathrm{KGaA}$ ) in PBS for $1 \mathrm{~h}$ at room temperature. Then, the cells were incubated with primary antibodies for $2 \mathrm{~h}$ at room temperature. Subsequently, the cells were incubated with the corresponding secondary antibodies and counterstained with DAPI (Dojindo Molecular Technologies, Inc., Kumamoto, Japan) at room temperature for $30 \mathrm{~min}$ prior to observation using the EVOS FL Imaging system (Thermo Fisher Scientific, Inc.).

Wound healing assay. Cell motility was assessed using a wound healing assay. Confluent cells were scratched with micropipette tips (Thermo Fisher Scientific, Inc.). Following washing with PBS, the cells were incubated for a further $9 \mathrm{~h}$ at $37^{\circ} \mathrm{C}$. Scratch areas were viewed using an inverted microscope (magnification, x10; Nikon Corporation, Tokyo, Japan) and 
-Control $\quad-$ TGF- $\beta+$ FGF-2

A

A-549

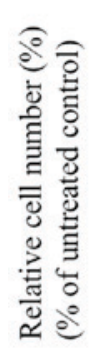

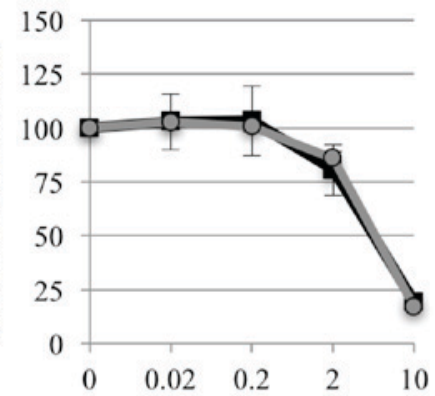

B

A-549

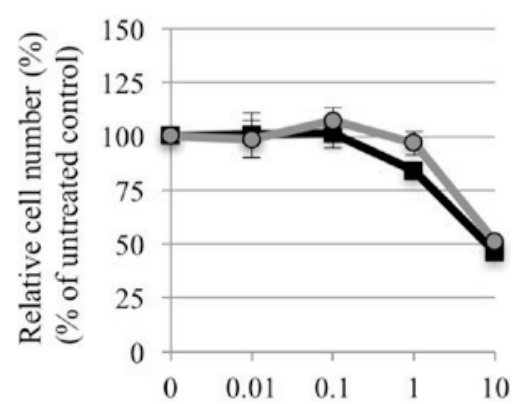

HCC-827

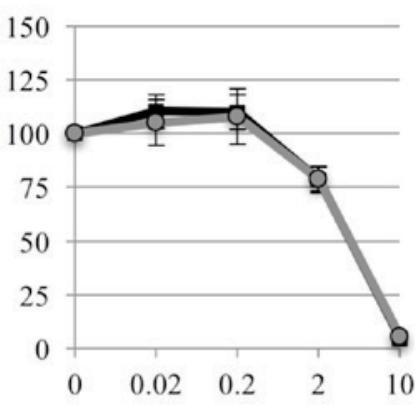

Pirfenidone (mM)
PC-9

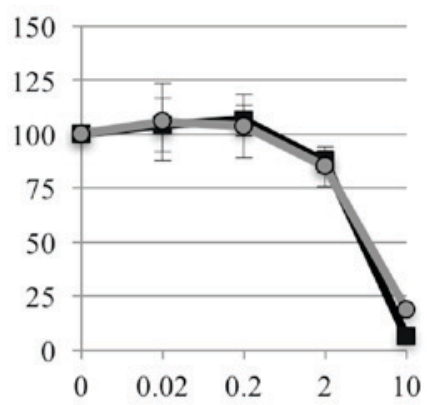

HCC-827

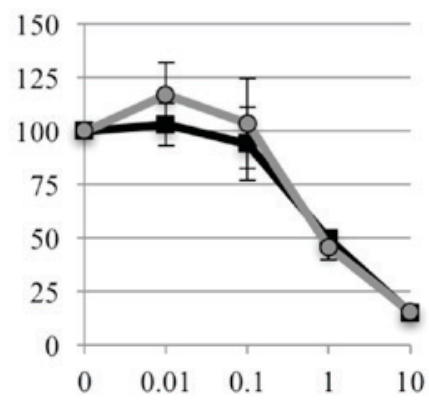

PC-9

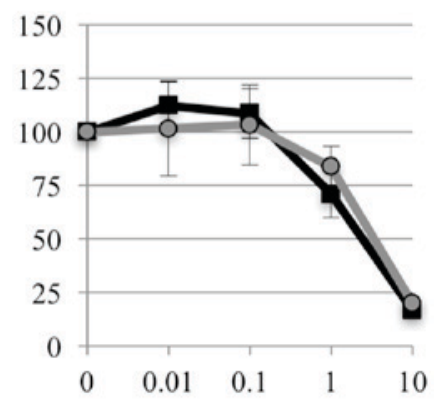

Nintedanib $(\mu \mathrm{M})$

Figure 1. (A and B) Inhibition of cell growth in A-549, HCC-827 and PC-9 cells by pirfenidone and nintedanib, as assessed using an MTT assay. Based on the results, doses of 0.2 and $2.0 \mathrm{mM}$ of pirfenidone, and 0.1 and $1.0 \mu \mathrm{M}$ of nintedanib were selected for subsequent experiments. Data are presented as the mean \pm standard error of the mean $(n=3$, in triplicate). TGF- $\beta$, transforming growth factor- $\beta$; FGF- 2 , fibroblast growth factor- 2 .

were quantified using Image J software (version $1.46 \mathrm{v}$; National Institutes of Health, Bethesda, MD, USA). The wound closure rates were determined as a percentage of the total repaired area per hour, and were normalized to the control.

Statistical analysis. Data are presented as the mean \pm standard error of the mean. Statistical analysis was performed using Microsoft Excel software (version 2010; Microsoft Corporation, Redmond, WA, USA). Differences between groups were analyzed using the two-tailed Student's t-test. $\mathrm{P}<0.05$ was considered to indicate a statistically significant difference. All experiments were repeated $\geq 3$ times, in triplicate.

\section{Results}

Cytotoxicity of pirfenidone and nintedanib. Fig. 1 shows the cytotoxicity of the agents, as assessed using the MTT assay. Based on these results, the borderline sublethal dose points, at which cell viability began to decline, and the adjacent lower dose point for each agent were selected for use in subsequent experiments $(0.2$ and $2.0 \mathrm{mM}$ for pirfenidone; 0.1 and $1.0 \mu \mathrm{M}$ for nintedanib).

In vitro induction of EMT. RT-qPCR in the three cell lines revealed that, compared with the untreated control group, the combination of TGF- $\beta$ and FGF-2 significantly downregulated E-cadherin and upregulated vimentin, fibronectin, and Slug, resulting in an EMT phenotype, with the exception of E-cadherin expression in PC-9 cells where no significant differences were observed (Fig. 2). Fluorescent immunohistochemical analysis of E-cadherin at the cell junction and fibronectin in the cytoplasm supported the results of the RT-qPCR analyses (Fig. 3). The wound-healing assay showed significantly increased cell motility associated with the EMT phenotype in A-549 and PC-9 cells (both $\mathrm{P}<0.05$ ), and a degree of increased cell motility in HCC-827 cells compared with the untreated control groups (Fig. 4A). The expression of PD-L1 assessed using RT-qPCR was significantly increased following EMT induction in all cell lines compared with the untreated cells (Fig. 4B). These findings appear to support the successful induction of EMT in all three cell lines.

Effects of pirfenidone and nintedanib on EMT-induced cells. Although no significant or consistent effects on the expression levels of E-cadherin and vimentin were observed, pirfenidone or nintedanib treatment at various doses significantly suppressed fibronectin and Slug expression levels compared with the EMT-phenotype control groups (Figs. 2 and 3). Furthermore, the wound healing assay results demonstrated that both of the agents significantly reverted the enhanced cell 
A-549

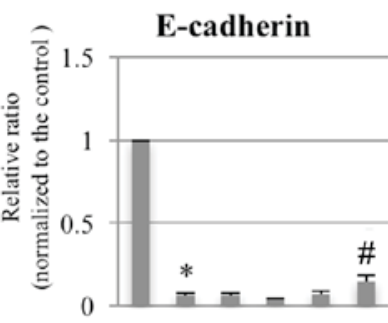

TGF-B

FGF-2

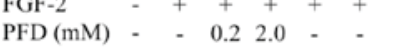

Nintedanib

$(\mu \mathrm{M})$

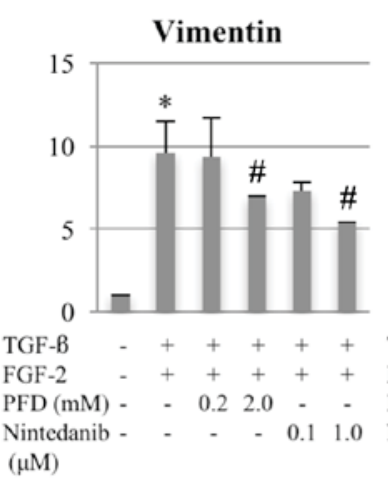

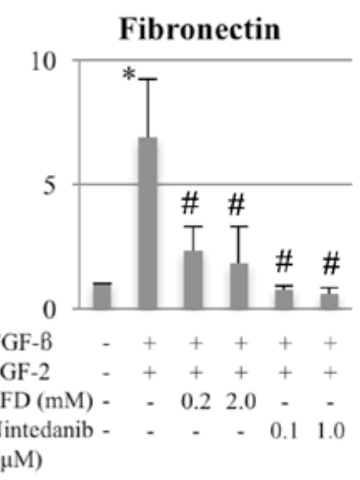

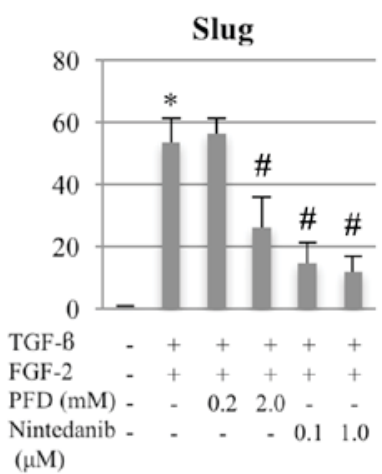

$(\mu \mathrm{M})$

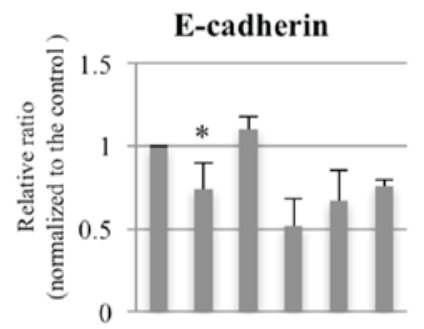

HCC-827
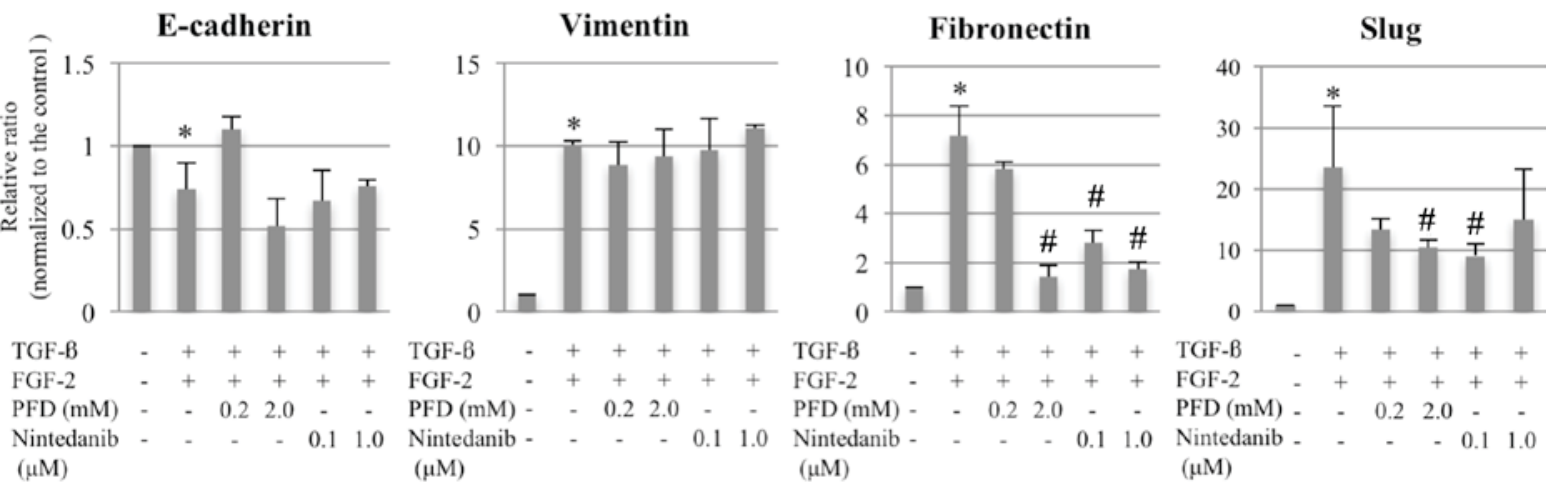

PC-9
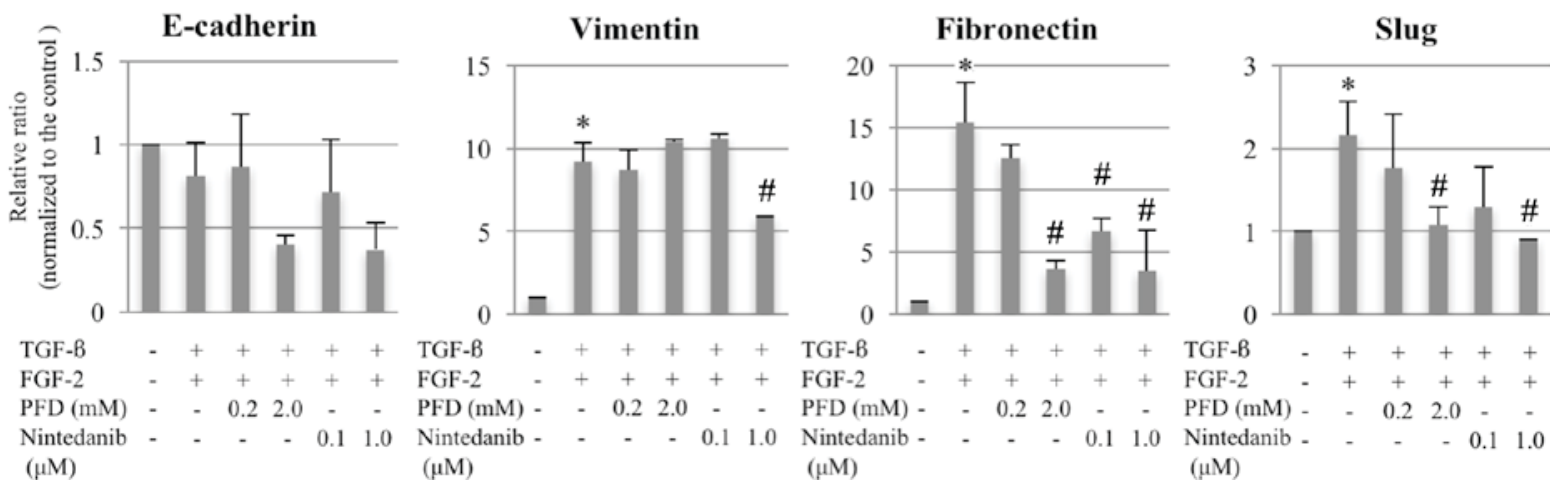

Figure 2. Changes in mRNA expression levels of E-cadherin, vimentin, fibronectin and Slug following EMT induction, and treatment with pirfenidone or nintedanib in A-549, HCC-827 and PC-9 cells. The relative ratios of mRNA in the treatment groups vs. the controls were evaluated using reverse transcription-quantitative polymerase chain reaction for cells treated with TGF- $\beta(10 \mathrm{ng} / \mathrm{ml})$ and FGF-2 (10 ng/ml). Following EMT induction, pirfenidone $(0.2$ or $2.0 \mathrm{mM})$ or nintedanib $(0.1$ or $1.0 \mu \mathrm{M})$ were added. Data are presented as the mean \pm standard error of the mean (n=6, in triplicate) of the relative ratios of expression compared with the levels of the respective controls. GAPDH was used for normalization. "P<0.05 compared with untreated control (no TGF- $\beta /$ FGF-2); ${ }^{~} \mathrm{P}<0.05$ compared with EMT-phenotype control (TGF- $\beta /$ FGF-2-treated cells). PFD, pirfenidone; TGF- $\beta$, transforming growth factor- $\beta$; FGF-2, fibroblast growth factor-2; EMT, epithelial-to-mesenchymal transition.

motility in all three cell lines compared with the EMT-phenotype control groups (Fig. 4A). Furthermore, following treatment with pirfenidone or nintedanib at various doses, PD-L1 expression was significantly downregulated compared with the EMT-induced cells, except in response to nintedanib in PC-9 cells (Fig. 4B).

\section{Discussion}

The present study demonstrated that a borderline sublethal dose of pirfenidone or nintedanib could revert the EMT phenotype that had been induced by a combination of TGF- $\beta$ and FGF- 2 in three different human lung adenocarcinoma cell lines. The altered expression of mesenchymal markers and Slug, together with the alteration to cell motility, support this observation. The present results are consistent with a previous report indicating that nintedanib suppressed the EMT in ovarian cancer cells (22). The same authors also reported that the promotion of E-cadherin expression in A-549 cells occurred through ZEB1 downregulation (22). Furthermore, nintedanib was demonstrated to inhibit TGF- $\beta$-induced myofibroblast differentiation through the inhibition of early events in TGF- $\beta$ signaling and 


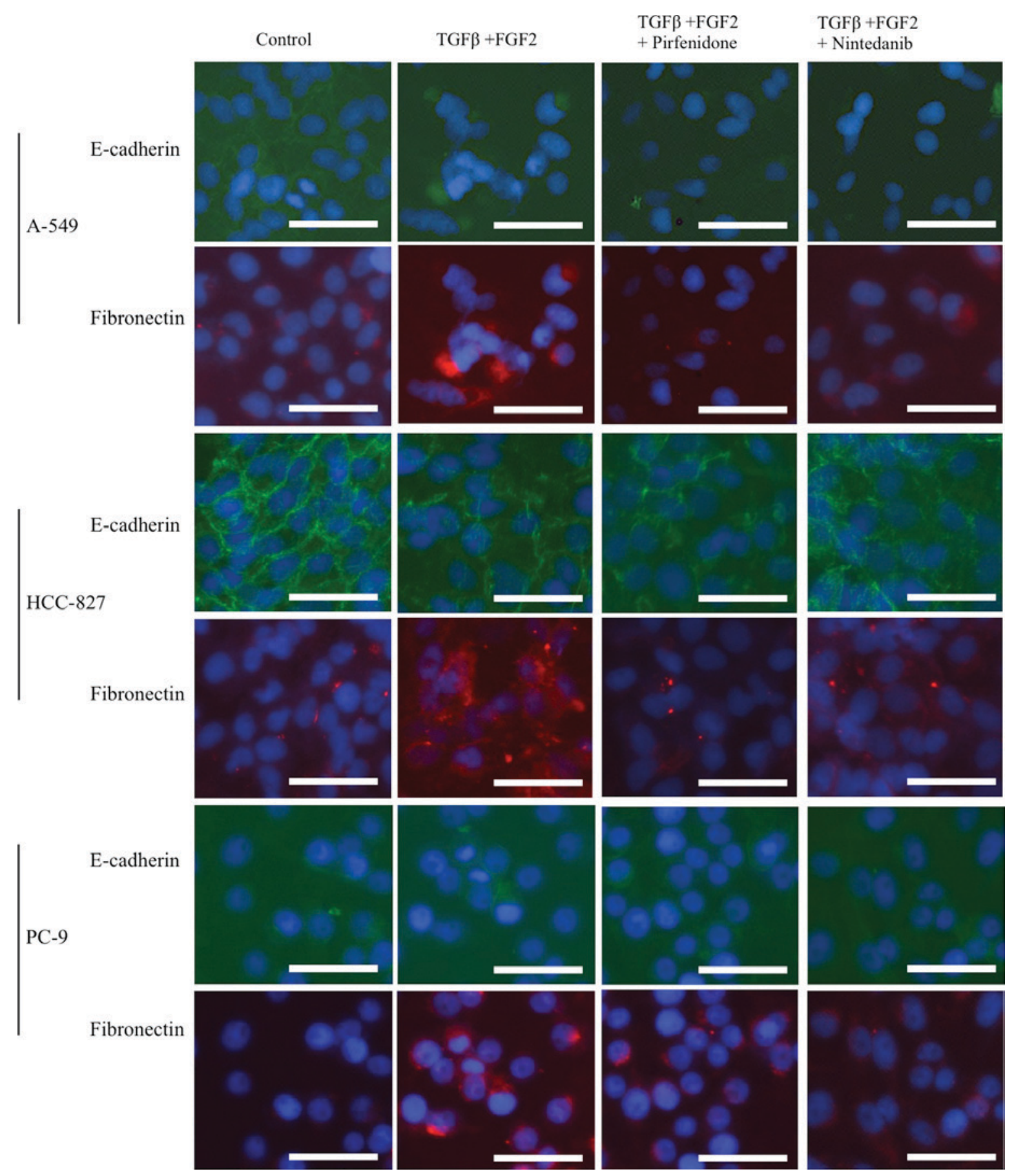

Figure 3. Fluorescent immunohistochemical staining for E-cadherin and fibronectin in A-549, HCC-827 and PC-9 cells shows the effects of epithelial-to-mesenchymal transition induction and its reversion by treatment with pirfenidone at a dose of $2.0 \mathrm{mM}$ or nintedanib at a dose of $1.0 \mu \mathrm{M}$. The changes in E-cadherin expression on the cell surfaces and the changes in fibronectin expression in the cytoplasm were confirmed. Cells were counterstained with DAPI. Scale bar, $50 \mu \mathrm{m}$. TGF- $\beta$, transforming growth factor- $\beta$; FGF-2, fibroblast growth factor-2 (n=3).

the activation of SMAD family member 3 (Smad3) in lung fibroblast cells (18). Therefore, the present study has provided novel evidence that pirfenidone possesses a similar ability to revert the EMT in human lung adenocarcinoma cells.

Previous studies have demonstrated that pirfenidone is able to suppress the differentiation of several cell types (24-28). Conte et al (24) reported that pirfenidone reduced fibroblast proliferation, attenuated TGF- $\beta$-induced $\alpha$-smooth muscle actin and inhibited the TGF- $\beta$-induced phosphorylation of Smad3 in human lung fibroblast cells. In addition, pirfenidone has been reported to suppress the differentiation of nasal polyp-derived fibroblasts (25), retinal pigment epithelial cells $(26,27)$ and cardiac fibroblasts (28). Kozono et al (29) reported that pirfenidone-treated pancreatic stellate cells suppressed the invasiveness and migration of pancreatic cancer cells. Pirfenidone's ability to induce EMT reversion in cancer cells may be similar to the previously reported findings. Furthermore, the present study confirmed the previously reported observation that PD-L1 expression was enhanced and suppressed according to the induction and reversion of EMT, respectively (30), suggesting the involvement of the EMT phenotype in the process of immune evasion in cancer. 
A

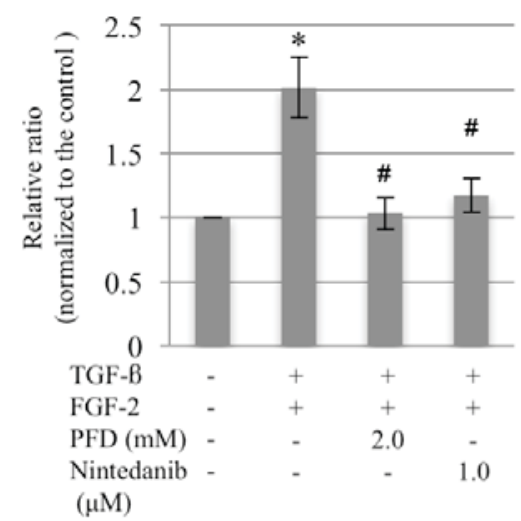

HCC-827

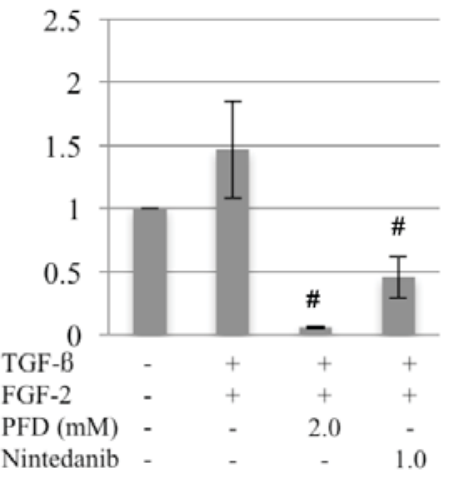

PC-9

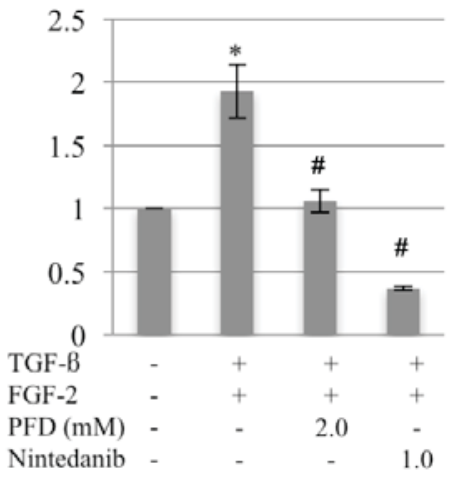

$(\mu \mathrm{M})$
B

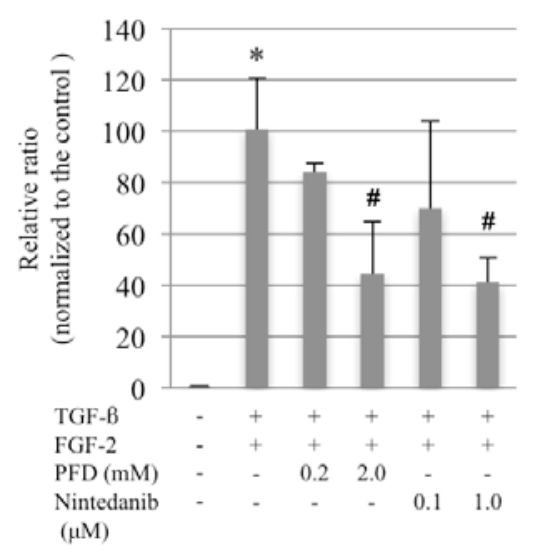

HCC-827

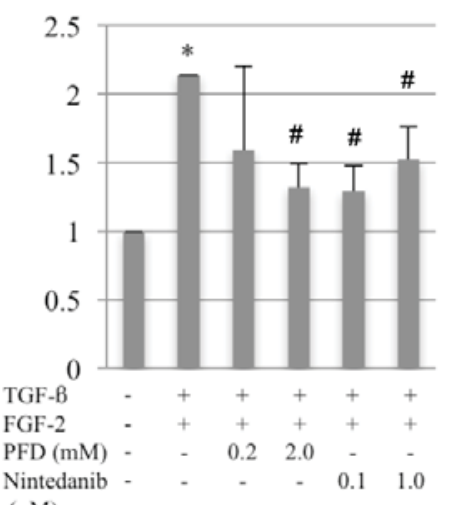

PC-9

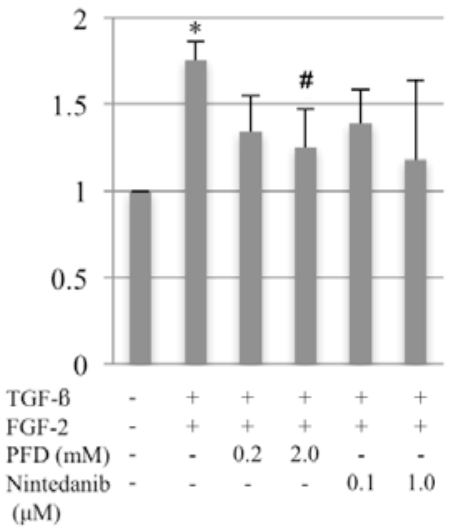

Figure 4. (A) A wound-healing assay showed enhanced cell motility following treatment with TGF- $\beta /$ FGF- 2 in all three cell lines, whereas pirfenidone and nintedanib suppressed the effect. For quantification, the cell migration distance was measured after $9 \mathrm{~h}$ ( $\mathrm{n}=9$, in triplicate) for each group. (B) Alteration of PD-L1 expression according to the induction and reversion of EMT. The relative mRNA expression of PD-L1 was normalized to that in the control. Data are presented as the mean \pm standard error of the mean $\left(n=3\right.$, in triplicate) of the relative ratio compared with the control. ${ }^{*} \mathrm{P}<0.05$ compared with untreated control (no. TGF- $\beta /$ FGF-2); ${ }^{\#} \mathrm{P}<0.05$ compared with EMT-phenotype control (TGF- $\beta / F G F-2$-treated cells). PFD, pirfenidone; TGF- $\beta$, transforming growth factor- $\beta$; FGF-2, fibroblast growth factor-2; EMT, epithelial-to-mesenchymal transition; PD-L1, programmed death-ligand 1.

The limitations of the present study should be considered when interpreting these results. Firstly, only the combination of TGF- $\beta$ and FGF- 2 was used to induce EMT, and other known EMT-inducing factors were not examined. Secondly, the important signaling pathways underlying EMT induction and reversion were not identified. Lastly, the study only included in vitro experiments, and thus may not reflect in vivo effects. Further studies associating the phenomena observed in the present study and investigations into their clinical relevance are warranted.

In conclusion, the results of the present study demonstrated that pirfenidone and nintedanib could each revert EMT induction and downregulate the expression of PD-L1 in human lung adenocarcinoma cells. Pirfenidone, thereby, may modify tumor progression and responsiveness to chemotherapy and/or immunotherapy for cancer.

\section{Acknowledgements}

The present study was supported by the Ministry of Education, Culture, Sports, Science and Technology in Japan (Kiban-C; grant no. 26461182).

\section{References}

1. Gavert $\mathrm{N}$ and Ben-Ze'ev A: Epithelial-mesenchymal transition and the invasive potential of tumors. Trends Mol Med 14: 199-209, 2008.

2. Thiery JP, Acloque H, Huang RY and Nieto MA: Epithelial-mesenchymal transitions in development and disease. Cell 139: 871-890, 2009.

3. Sato M, Shames DS and Hasegawa Y: Emerging evidence of epithelial-to-mesenchymal transition in lung carcinogenesis. Respirology 17: 1048-1059, 2012.

4. Shirakihara T, Horiguchi K, Miyazawa K, Ehata S, Shibata T, Morita I, Miyazono K and Saitoh M: TGF- $\beta$ regulates isoform switching of FGF receptors and epithelial-mesenchymal transition. EMBO J 30: 783-795, 2011.

5. Kurimoto R, Iwasawa S, Ebata T, Ishiwata T, Sekine I, Tada Y, Tatsumi K, Koide S, Iwama A and Takiguchi Y: Drug resistance originating from a TGF- $\beta /$ FGF-2-driven epithelial-to-mesenchymal transition and its reversion in human lung adenocarcinoma cell lines harboring an EGFR mutation. Int $\mathbf{J}$ Oncol 48: 1825-1836, 2016.

6. Lamouille S and Derynck R: Cell size and invasion in TGF-beta-induced epithelial to mesenchymal transition is regulated by activation of the mTOR pathway. J Cell Biol 178: 437-451, 2007.

7. Li L, Han R, Xiao H, Lin C, Wang Y, Liu H, Li K, Chen H, Sun F, Yang Z, et al: Metformin sensitizes EGFR-TKI-resistant human lung cancer cells in vitro and in vivo through inhibition of IL-6 signaling and EMT reversal. Clin Cancer Res 20: 2714-2726, 2014. 
8. Noble PW, Albera C, Bradford WZ, Costabel U, Glassberg MK, Kardatzke D, King TE Jr, Lancaster L, Sahn SA, Szwarcberg J, et al: Pirfenidone in patients with idiopathic pulmonary fibrosis (CAPACITY): Two randomised trials. Lancet 377: 1760-1769, 2011

9. Taniguchi H, Ebina M, Kondoh Y, Ogura T, Azuma A, Suga M, Taguchi Y, Takahashi H, Nakata K, Sato A, et al: Pirfenidone in idiopathic pulmonary fibrosis. Eur Respir J 35: 821-829, 2010.

10. Iyer SN, Gurujeyalakshmi G and Giri SN: Effects of pirfenidone on procollagen gene expression at the transcriptional level in bleomycin hamster model of lung fibrosis. J Pharmacol Exp Ther 289: 211-218, 1999.

11. Iyer SN, Gurujeyalakshmi G and Giri SN: Effects of pirfenidone on transforming growth factor-beta gene expression at the transcriptional level in bleomycin hamster model of lung fibrosis J Pharmacol Exp Ther 291: 367-373, 1999.

12. Gurujeyalakshmi G, Hollinger MA and Giri SN: Pirfenidone inhibits PDGF isoforms in bleomycin hamster model of lung fibrosis at the translational level. Am J Physiol 276: L311-L318, 1999.

13. Di Sario A, Bendia E, Svegliati Baroni G, Ridolfi F, Casini A, Ceni E, Saccomanno S, Marzioni M, Trozzi L, Sterpetti P, et al: Effect of pirfenidone on rat hepatic stellate cell proliferation and collagen production. J Hepatol 37: 584-591, 2002.

14. Garcia L, Hernández I, Sandoval A, Salazar A, Garcia J, Vera J, Grijalva G, Muriel P, Margolin S and Armendariz-Borunda J: Pirfenidone effectively reverses experimental liver fibrosis. J Hepatol 37: 797-805, 2002.

15. Richeldi L, Costabel U, Selman M, Kim DS, Hansell DM, Nicholson AG, Brown KK, Flaherty KR, Noble PW, Raghu G, et al: Efficacy of a tyrosine kinase inhibitor in idiopathic pulmonary fibrosis. N Engl J Med 365: 1079-1087, 2011.

16. Richeldi L, du Bois RM, Raghu G, Azuma A, Brown KK, Costabel U, Cottin V, Flaherty KR, Hansell DM, Inoue Y, et al: Efficacy and safety of nintedanib in idiopathic pulmonary fibrosis. N Engl J Med 370: 2071-2082, 2014.

17. Wollin L, Maillet I, Quesniaux V, Holweg A and Ryffel B: Antifibrotic and anti-inflammatory activity of the tyrosine kinase inhibitor nintedanib in experimental models of lung fibrosis J Pharmacol Exp Ther 349: 209-220, 2014.

18. Rangarajan S, Kurundkar A, Kurundkar D, Bernard K, Sanders YY, Ding Q, Antony VB, Zhang J, Zmijewski J and Thannickal VJ: Novel mechanisms for the Antifibrotic action of Nintedanib. Am J Respir Cell Mol Biol 54: 51-59, 2016.

19. Turner-Warwick M, Lebowitz M, Burrows B and Johnson A: Cryptogenic fibrosing alveolitis and lung cancer. Thorax 35: 496-499, 1980
20. Hubbard R, Venn A, Lewis S and Britton J: Lung cancer and cryptogenic fibrosing alveolitis. A population-based cohort study. Am J Respir Crit Care Med 161: 5-8, 2000.

21. Matsushita H, Tanaka S, Saiki Y, Hara M, Nakata K, Tanimura S and Banba J: Lung cancer associated with usual interstitial pneumonia. Pathol Int 45: 925-932, 1995

22. Huang RY, Kuay KT, Tan TZ, Asad M, Tang HM, Ng AH, Ye J, Chung VY and Thiery JP: Functional relevance of a six mesenchymal gene signature in epithelial-mesenchymal transition (EMT) reversal by the triple angiokinase inhibitor, nintedanib (BIBF1120). Oncotarget 6: 22098-22113, 2015.

23. Livak KJ and Schmittgen TD: Analysis of relative gene expression data using real-time quantitative PCR and the 2(-Delta Delta C(T)) method. Methods 25: 402-408, 2001.

24. Conte E, Gili E, Fagone E, Fruciano M, Iemmolo M and Vancheri C: Effect of pirfenidone on proliferation, TGF- $\beta$-induced myofibroblast differentiation and fibrogenic activity of primary human lung fibroblasts. Eur J Pharm Sci 58: 13-19, 2014

25. Shin JM, Park JH, Park IH and Lee HM: Pirfenidone inhibits transforming growth factor $\beta 1$-induced extracellular matrix production in nasal polyp-derived fibroblasts. Am J Rhinol Allergy 29: 408-413, 2015.

26. Choi K, Lee K, Ryu SW, Im M, Kook KH and Choi C: Pirfenidone inhibits transforming growth factor- $\beta 1$-induced fibrogenesis by blocking nuclear translocation of Smads in human retinal pigment epithelial cell line ARPE-19. Mol Vis 18: 1010-1020, 2012.

27. Wang J, Yang Y, Xu J, Lin X, Wu K and Yu M: Pirfenidone inhibits migration, differentiation, and proliferation of human retinal pigment epithelial cells in vitro. Mol Vis 19: 2626-2635, 2013.

28. Shi Q, Liu X, Bai Y, Cui C, Li J, Li Y, Hu S and Wei Y: In vitro effects of pirfenidone on cardiac fibroblasts: Proliferation, myofibroblast differentiation, migration and cytokine secretion. PLoS One 6: e28134, 2011.

29. Kozono S, Ohuchida K, Eguchi D, Ikenaga N, Fujiwara K, Cui L, Mizumoto $\mathrm{K}$ and Tanaka M: Pirfenidone inhibits pancreatic cancer desmoplasia by regulating stellate cells. Cancer Res 73: 2345-2356, 2013.

30. Chen L, Gibbons DL, Goswami S, Cortez MA, Ahn YH, Byers LA, Zhang X, Yi X, Dwyer D, Lin W, et al: Metastasis is regulated via microRNA-200/ZEB1 axis control of tumour cell PD-L1 expression and intratumoral immunosuppression. Nat Commun 5: 5241, 2014 